\title{
Fungicides for Control of Rice Blast Disease
}

\author{
Isamu YAMAGUCHI \\ The Institute of Physical and Chemical Research, \\ Hirosawa, Wako, Saitama 351, Japan
}

Rice blast disease, caused by the fungus Pyricularia oryzae, has been observed in almost every rice-growing country, and is the most serious and damaging of all diseases in temperate and humid climates, such as Japan. ${ }^{1)}$ Since the disease has caused significant yield losses in the annual production of rice which is the principal axis of agriculture in this country, ${ }^{2)}$ the greatest precautions have long been taken for the control of the disease. Organomercuric compounds were initially introduced for seed treatment in 1915 and have been applied in fields for the control of rice blast since 1953; this practice contributed greatly to the protection of rice plant against the disease and resulted in increased rice production. In 1956, however, mercuric poisoning was reported and demonstrated by "Minamata disease" in Kumamoto Prefecture and a later disease on the Agano River basin in Niigata Prefecture (1964). Though these diseases were shown to be caused by industrial wastes and not by agricultural mercuric chemicals, the residual accumulation of organomercuric compounds in the human body has become a serious problem. Thus, fear for dreadful mercuric poisoning caused the 1968 legal prohibition of organomercuric chemicals for agricultural use.

Since rice blast is one of Japan's most important disease problems, as mentioned above, the necessity for non-mercuric chemicals to control it was essential and urgent. As a result of earnest research, many excellent blast-controllers were discovered and some were developed for practical use. Table 1 shows the main anti-blast chemicals used in Japan at present. There are many other compounds which have been developed for blast control, such as $O, O$-diethyl $S$-benzyl phos- phorothiolate (EBP, Kitazin ${ }^{\circledR}$ ), S-benzyl ethyl phenylphosphonothiolate (Inezin ${ }^{\circledR}$ ), pentachlorobenzyl alcohol (Blastin $\left.{ }^{\circledR}\right)$, pentachlorophenyl acetate (Rabcon $\left.{ }^{\circledR}\right) .{ }^{1)}$ Some have been replaced by more effective related compounds, and others abandoned for economic reasons after the revised tightening of the rule legislated in 1971. Thus, during the last 30 years anti-blast fungicides have primarily been developed in Japan and, compared with agricultural chemicals for fruits and vegetables, they have a unique feature in research history.

It is said that the exploitation and development of new fungicides have become extremely difficult in recent years. One reason for this is supposedly an economic one, because expensive studies on the toxicity of the chemicals and residue analyses in crops, animals and the environment are needed to secure registration and to protect human health. Another recent problem is the development of resistance in pathogens due to the wide use of site specific chemicals. Actually, in 1971 resistance against kasugamycin was recognized in the Shonai district of Yamagata Prefecture ${ }^{3)}$ and resistant isolates of organophosphorus thiolate fungicides were obtained from the field in Niigata and Toyama Prefecture in 1976.,5) One of the solutions to the problem would be to contrive ingenious ways for the effective usage of the chemicals in hand. Therefore, in this paper, characteristics of the blast-controllers used in practical control will be discussed, mainly in terms of their modes of action. This may hopefully suggest the qualities that ideal anti-blast fungicides should possess.

\section{BLASTICIDIN S AND KASUGAMYCIN}

By aiming only at protection of plant di- 


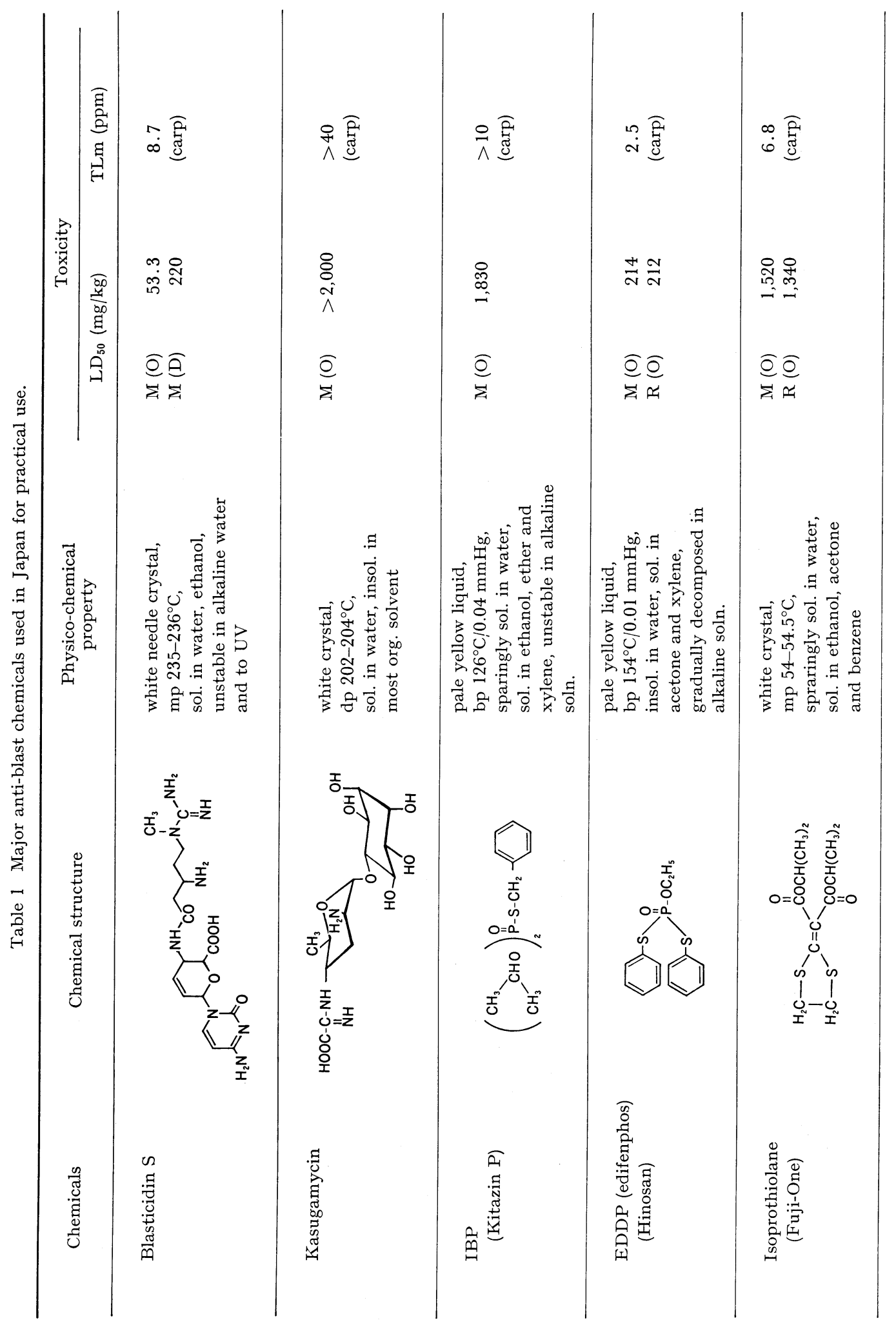




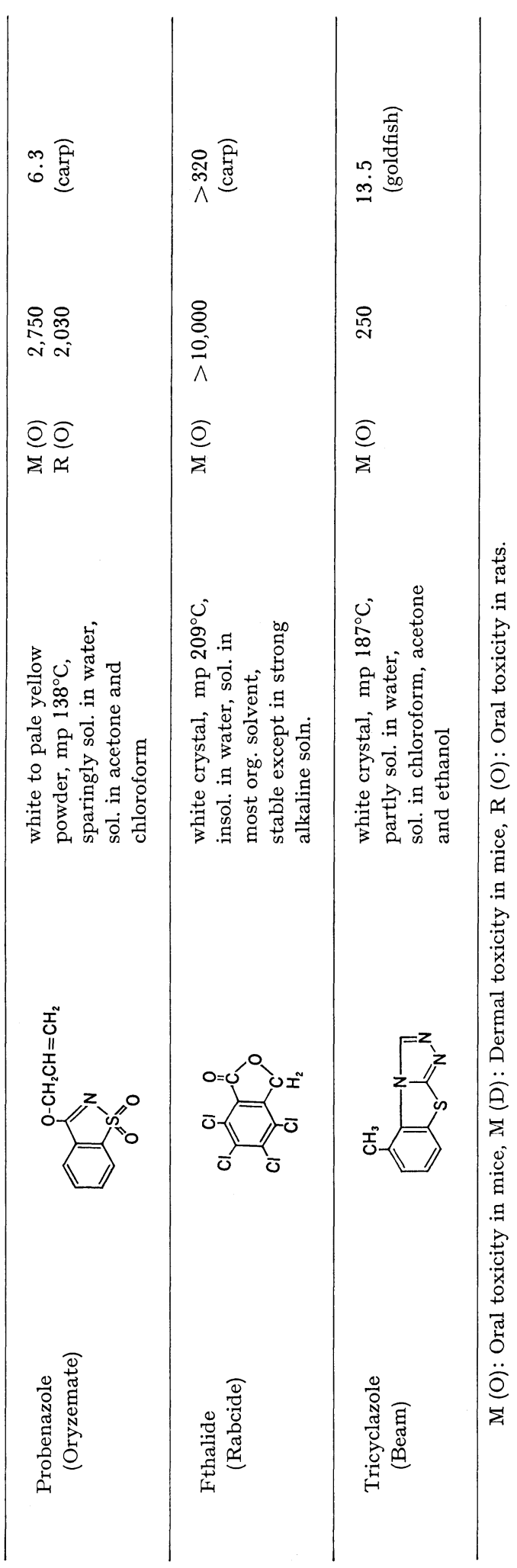

sease, blasticidin $\mathrm{S}$ was the first successful agricultural antibiotic developed in Japan. It was isolated in 1958 by Takeuchi et al. ${ }^{6)}$ from the culture filtrate of Streptomyces griseochromogenes, and its curative effect on rice blast was found and evaluated in field trials in 1959-1960. ${ }^{7}$ The effective concentration for spraying blasticidin $\mathrm{S}$ is quite low (usually 10-20 ppm; $1-3 \mathrm{~g} / 10 \mathrm{a}$ ), but when sprayed at higher concentrations, the antibiotic occasionally causes chemical injury to rice leaves. Such phytotoxic effects were also observed on other crops such as tobacco plant, eggplant, tomato and beans. Benzylaminobenzene sulfonate of blasticidin $\mathrm{S}$ was found to be least phytotoxic to rice plant without reducing control efficacy ${ }^{8)}$ and has been industrially produced for practical use.

The chemical structure of blasticidin $\mathrm{S}$ was elucidated by Yonehara and Ōtake, ${ }^{9)}$ as shown in Table 1. Biosynthesis of the antibiotic revealed that the pyrimidine ring came from cytosine and the sugar from glucose; the amino acid portion originated from arginine and methionine. ${ }^{10)}$ Such unique structure and wide spectrum of the antibiotic against fungi, bacteria and viruses lead to the study of its biochemical properties. Misato and coworkers $^{11-13)}$ found that blasticidin S markedly inhibited the protein synthesis of $P$. oryzae without affecting other metabolic pathways. Further, the antibiotic was shown to act in the step of peptide transfer from peptidyl-t RNA with the incoming aminoacyl-t RNA on the ribosomes in the cell free system of Escherichia coli. ${ }^{14)}$ (Fig. 1).

Application of blasticidin S by dusting had occasionally caused conjunctivitis if the dust accidentally came in contact with the eyes, and this toxic effect was the most unfavorable characteristic of the antibiotic. Many attempts have been made to overcome the defect, e.g., biological transformation ${ }^{15,16)}$ or the addition of detoxifying agents. ${ }^{17,18)}$ Nowadays an improved dust formulation which contains $5 \%$ calcium acetate is used to alleviate eye trouble, together with harmless wettable powder or emulsion.

The behavior and fate of blasticidin $\mathrm{S}$ in the environment were investigated in the model system using ${ }^{14} \mathrm{C}$-compounds prepared 


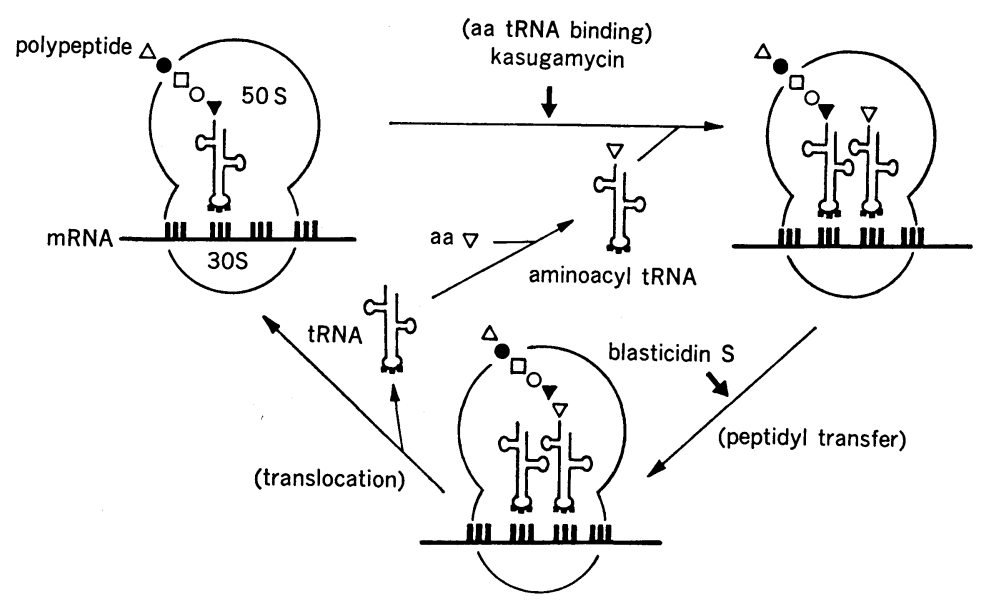

Fig. 1 Protein synthesis and sites of inhibition by blasticidin S and kasugamycin.

biosynthetically, and it was indicated that the antibiotic was rapidly broken down by sunlight or in the soil. ${ }^{19)}$ The residue analysis of blasticidin $\mathrm{S}$ in rice showed no food contamination. ${ }^{20)}$

Another anti-blast antibiotic, kasugamycin, is an aminoglycoside isolated from Streptomyces kasugaensis by Umezawa et al. ${ }^{21)}$ in 1965. Its chemical structure ${ }^{22}$ is shown in Table 1. The antifungal activity of kasugamycin is not too significant in vitro (at neutral $\mathrm{pH})$, but it indicated marked curative effect against rice blast in a pot test in vivo. ${ }^{23}$ ) This remarkable finding caused most screening systems thereafter to be carried out by the pot test, though later it was found that kasugamycin exhibits inhibition of fungal growth specifically at $\mathrm{pH}$ 4.5-5.0, which roughly coincides with the hydrogen ion concentration in the tissue of rice plant.

As shown in Table 1, mammalian toxicity of kasugamycin is quite low and no phytotoxicity was observed to most crops including rice plant. Thus it has been safely used for the protection of blast disease, reduction of its efficacy, however, being gradually recognized in the northeastern part of Japan after its introduction into practical use. ${ }^{3)}$ The appearance of resistant strains was supposed to be caused by the selection of spontaneous mutants through intensive and successive application of the antibiotic. Fortunately, however, once the use of kasugamycin was stopped, the proportion of resistant strains in the field decreased rapidly and susceptible ones became predominant within a few years. ${ }^{24)}$ Thus, the combined or cycle use of protectants with different mechanisms of action was recommended, particularly in the case of site specific chemical application against $P$. oryzae, which is liable to mutate and consists of variable races.

Kasugamycin inhibits protein synthesis of $P$. oryzae or $E$. coli. ${ }^{25)}$ Aminoglycoside antibiotics generally prevent protein synthesis by causing miscoding (codon misreading), whereas kasugamycin was indicated to specifically interfere with the formation of the initiation complex, i.e., the binding of aminoacyl-t RNA to the mRNA-30S ribosomal subunit (Fig. 1). The ribosomes from resistant clones obtained in vitro were shown not to be susceptible to kasugamycin. ${ }^{26)}$ The remarkable difference between microbial and mammalian sensitivity may be explained by the diversity of the initiation complex or ribosomal nature.

\section{IBP, EDDP AND ISOPROTHIOLANE}

Since the discovery of antifungal activity of EBP (Kitazine ${ }^{\circledR}$ ), ${ }^{27)}$ organophosphorus compounds have become the major group of antiblast fungicides. The organophosphorus thiolate (PTL) fungicides, diisopropyl $S$-benzyl phosphorothiolate ${ }^{28)}$ (IBP, Kitazine $\mathrm{P}^{\circledR}$ ) and ethyl $S, S$-diphenyl phosphorodithiolate ${ }^{29}$ 
(EDDP; edifenphos, Hinosan ${ }^{\circledR}$ ), have been widely used for the practical control of blast disease (Table 1). IBP has high water solubility for organophosphorus fungicides and is systemic to the rice plant, favoring its application to the paddy water surface. EDDP is not systemic but has a potent antifungal activity against the blast fungus, and thus it provides effective blast control with foliar application. ${ }^{30)}$ The chemical structure of isoprothiolane $^{31)}$ (diisopropyl 1,3-dithiolan-2ylidenmalonate, Fuji One, ${ }^{\circledR}$ Table 1) is seemingly different from those of PTL fungicides; it lacks a phosphorus atom and the sulfur atoms are in a thio-ether form instead of thioester form. Nevertheless, cross-resistance between isoprothiolane and PTL fungicides suggests a close similarity in mode of action of these compounds. ${ }^{32)}$

IBP causes an inhibition of the incorporation of ${ }^{14} \mathrm{C}$-glucosamine into the cell wall chitin of $P$. oryzae, concomitantly inducing an accumulation of UDP- $N$-acetyl glucosamine. ${ }^{33)}$ It has been suggested, therefore, that IBP inhibits the action of chitin synthetase or the passage of some lipophilic chitin precursors through the cytoplasmic membrane. Similar results were obtained with EDDP, and the leakage of ${ }^{32} \mathrm{P}$ from the mycelia into the medium was shown. ${ }^{34)}$ IBP and EDDP, however, were also observed to inhibit the growth of Pythium debaryanum, a fungus which is supposed to be free of chitin. Thus it was suggested that the interference with cell membrane permeability is primarily responsible for the fungitoxicity of the chemicals rather

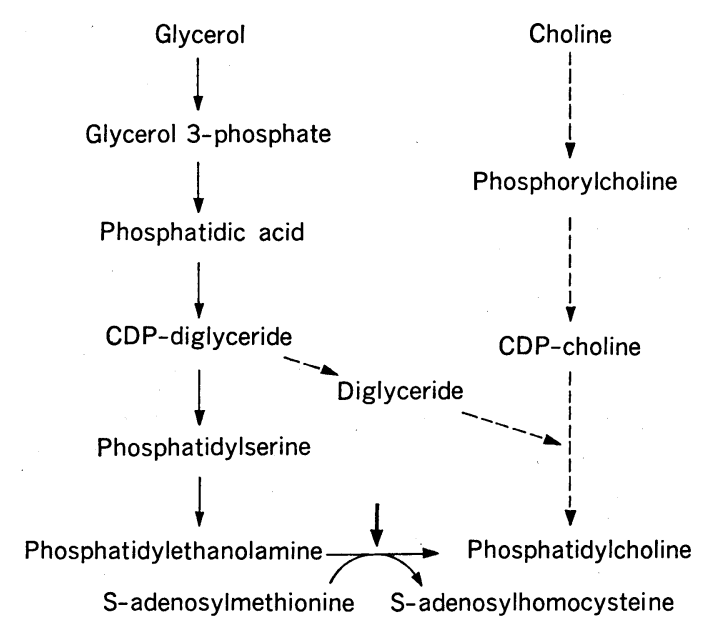

Fig. 2 Phospholipid biosynthetic pathway and possible site of inhibition by phosphorothiolate fungicides and isoprothiolane.

than the direct inhibition of chitin synthesis. ${ }^{34)}$ In connection with this, Kodama et al. recently reported that IBP and EDDP specifically inhibit the conversion of phosphatidylethanolamine to phosphatidylcholine ${ }^{35,36)}$ (Fig. 2). Upon incubation of mycelial suspensions of $P$. oryzae with IBP or EDDP, a striking decrease was induced in incorporation of methionine-methyl- ${ }^{14} \mathrm{C}$ or glycerol- $1-{ }^{14} \mathrm{C}$ into phosphatidylcholine, the major phospholipid in the fungus. The concentrations of fungicides required for $50 \%$ inhibition of phospholipid $N$-methyltransferase essentially coincided with $\mathrm{ED}_{50}$ values for the inhibition of fungal growth. In contrast, inhibition of chitin synthesis took place only at higher

Table 2 Inhibitory effect of chemicals on P. oryzae in vitro and on disease development.

\begin{tabular}{|c|c|c|c|}
\hline \multirow{2}{*}{ Chemicals } & \multicolumn{3}{|c|}{$\mathrm{ED}_{95}(\mu \mathrm{g} / \mathrm{ml})$} \\
\hline & $\begin{array}{c}\text { Mycelial } \\
\text { growth }\end{array}$ & $\begin{array}{c}\text { Spore } \\
\text { germination }\end{array}$ & $\begin{array}{c}\text { Disease } \\
\text { development }\end{array}$ \\
\hline Blasticidin S & $<1$ & $50<$ & $1-5$ \\
\hline Kasugamycin & $<1$ & $200<$ & $2-5^{a)}$ \\
\hline IBP & $<10$ & $<30$ & $10-30^{a)}$ \\
\hline EDDP & $<50$ & $<10$ & $5-20$ \\
\hline Isoprothiolane & 40 & 200 & $1-5^{a)}$ \\
\hline Probenazole & $400<$ & $50<$ & $5-20$ \\
\hline Fthalide & $1,000<$ & $1,000<$ & $5-10^{\mathrm{a})}$ \\
\hline Tricyclazole & $500<$ & $400<$ & $1-5$ \\
\hline
\end{tabular}

a) F. Araki \& Y. Miyagi: J. Pesticide Sci. 2, 457 (1977) 
concentration of the chemicals. Inasmuch as phospholipid is an essential component of the fungal membrane constituting the structure and function, the inhibition of phosphatidylcholine synthesis will induce alteration of membrane permeability or deterioration of enzyme activities associated with membrane, e.g., cytochrome P-450 catalyzed reaction.

Isoprothiolane is a systemic fungicide effective in controlling the blast by treatment through the root system. ${ }^{31)}$ Its efficacy on the host plant is greater than that expected from the fungitoxicity of the compound in vitro, because isoprothiolane primarily prevents the invasion process of the fungus into the host plant $^{37,38)}$ (Table 2). Isoprothiolane inhibits the incorporation of ${ }^{14} \mathrm{C}$-acetate into fatty acids and triglycerides in mycelia of $P$. oryzae. Incorporation of methionine-methyl- ${ }^{14} \mathrm{C}$ into phospholipid was also remarkably reduced by isoprothiolane as in the case of IBP and EDDP, and $S$-adenosylmethionine was observed to accumulate in the treated mycelia. ${ }^{39)}$ Other metabolic processes including chitin synthesis were not influenced by the chemical except that the uptake of ${ }^{14} \mathrm{C}$-sugars by the cell and the incorporation of ${ }^{14} \mathrm{C}$-sugar into the cell wall were inhibited. ${ }^{40)}$ Therefore, it is suggested that isoprothiolane acts on the synthesis of cell membrane/wall or on the transport system of membrane, though details of the mechanism of action remain to be solved in the future.

As described earlier, the development of resistance to IBP in the paddy field was recognized in 1976. ${ }^{4}$ Prior to isolation of resistant strains, however, possible problems were predicted by Uesugi et al. ${ }^{41)}$ because of the narrow selectivity in the toxicity of PTL fungicides. As the resistance of insects to organophosphorus insecticides was already known and was mostly attributed to the development of detoxification ability in the insect body, the metabolism of PTL fungicides has been intensively studied. But no difference in mode or rate of metabolism was found between the wild type isolate and its PTL-resistant clone selected in the laboratory to IBP or EDDP. ${ }^{42,43)}$ In the course of study, Uesugi et al. found negatively correlated cross resistance and synergism between certain phosphoramidate compounds and PTL fungicides or isoprothiolane. ${ }^{32,44)}$ While this collateral sensitivity was expected to solve the resistance problem, such correlation was not found in most of the PTL-resistant field isolates. ${ }^{5)}$ Instead, a higher rate of PTL metabolic activity was observed in the resistant isolates and this increased detoxification was supposed to be a reason for decline of sensitivity to the fungicides due to the enhanced activity of mixed function oxidase (mfo). ${ }^{45}$ Metabolism and residual fate of IBP and EDDP in rice plant were extensively studied, and it was shown that the main metabolic pathway of IBP was dependent on the hydrolysis to produce diisopropyl hydrogen phosphorothioate and EDDP was metabolized through the cleavage of P-S bond to produce benzenethiol and its oxidation products. ${ }^{46,47)}$ It is probable that the difference of benzyl and phenyl radicals in the fungicides determines the pattern of metabolism, and consequently terminal residues. No toxic metabolites have been reported so far and thus the use of PTL fungicides would appear not to cause a hazard to mammals and to the environment.

\section{PROBENAZOLE, FTHALIDE AND TRICYCLAZOLE}

Anti-blast chemicals such as probenazole ${ }^{48)}$ (3 - allyloxy - 1,2 - benzisothiazole - 1, 1 - dioxide, Oryzemate $\left.^{\circledR}\right)$, fthalide ${ }^{49)} \quad(4,5,6,7$-tetrachlorophthalide, Rabcide $\left.{ }^{\circledR}\right)$ and tricyclazole ${ }^{50)}$ [5methyl-1,2,4-triazolo-(3,4-b) - benzothiazole, Beam $\left.{ }^{\circledR}\right]$ perform outstanding control of blast disease in vivo, but are primarily not toxic to the vegetative growth of $P$. oryzae in vitro. As shown in Table 2, the disease-control activity of antibiotics or PTL fungicides is more or less relevant to their fungitoxicity in vitro, whereas there are great differences in the effective concentration between in vitro and in vivo for probenazole, fthalide and tricyclazole. The anti-blast action of such non-fungicidal compounds must be sought in the suppression of pathogenic activity in $P$. oryzae, the alteration of the chemicals in host plants to fungitoxic metabolites or the accentuation of plant resistance mechanism.

Probenazole is a systemic agent which is 


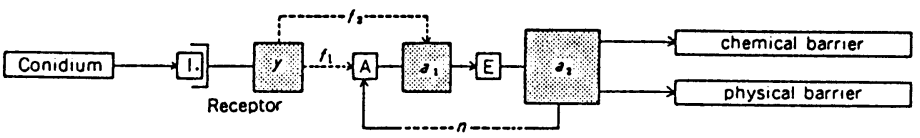

Scheme 1 A first model of the signal transmission hypothesis upon the resistance mechanism of rice plant. (by Y. Sekizawa)

I: Inducer in blast fungus conidium or mycelium,

$\mathrm{A}$ and $\mathrm{E}$ : Chemical mediators,

$y, a_{1}$, and $a_{2}$ : Black boxes,

$f_{1}$ and $f_{2}$ : Transmission pathway from receptor,

$n$ : Negative feedback regulation.

quite effective against blast disease when applied to the root system of rice plant. ${ }^{48)}$ Neither its metabolites nor degraded products in rice plant or irrigation water exhibited any in vitro fungi-toxic activity. ${ }^{51,52)}$ Instead, probenazole was shown to strongly enhance the resistance mechanism in rice plant against the fungal penetration into the leaf cells and subsequently the extension of invading hypha to adjacent cells. ${ }^{53)}$ The application of probenazole to rice plant inoculated with conidia of $P$. oryzae induced anti-microbial subtances such as $\alpha$-linolenic acid and also augmented enzyme activities related to form a lignoid barrier at the invaded cells. ${ }^{54)}$ The long lasting activity of probenazole was, therefore, attributed to this host mediated defense action (Scheme ${ }^{55)}$ ).

Fthalide has a potent protective activity against rice blast with long residual effectiveness. In fact, two foliar applications of fthalide after the heading stage of plant growth provided excellent prevention of panicle blast ${ }^{49}$ ) which destructively reduces the quality of rice grains and the quantity of yield. Such marked protective effect was also observed in the application of pentachlorobenzyl alcohol (PCBA), ${ }^{56)}$ another expected organochlorine fungicide, the use of which, however, was stopped because of the phytotoxic effect of metabolites on the seedlings of tomato or cucumber. ${ }^{57)}$ Thus, metabolic fate and behavior of fthalide were examined in detail but no chlorinated benzoic acids, the phytotoxic metabolites of PCBA, were detected in compost treated with the chemical. ${ }^{58)}$ A characteristic feature of fthalide is its remarkably low toxicity to mammals (Table 1) and, similarly, the main metabolites were indi- cated to be scarcely toxic with negligible phytotoxicity on vegetables. ${ }^{58)}$

On the host plant, fthalide reduces the formation of appressoria and inhibits the invasion process of $P$. oryzae most significantly. ${ }^{49}$ The same tendency was observed in the test using artificial membranes like cellophane or collodion film ${ }^{59}$ as was known for $\mathrm{PCBA},{ }^{60}{ }^{\circ}$ and thus it does not seem that the inhibition by fthalide is caused by the host mediated action. Though the detailed mechanism of action still remains obscure, Chida et al. revealed that the chemical completely inhibits the formation of infection-peg in the appressorium of $P$. oryzae. ${ }^{61)}$ Therefore, it may act on the maturing process of appressorium prior to infection-peg formation by the blast fungus.

Tricyclazole is a highly potent systemic protectant recently registered in Japan for the control of rice blast. It allows spore germination, appressorial formation and mycelial growth of $P$. oryzae in vitro but specifically prevents penetration by the fungus into rice tissue. ${ }^{50,62)}$ In vivo activity was 25 to 35 times greater than in vitro activity. The chemical also inhibited secondary infection under field conditions by reducing the sporulation of $P$. oryzae. Field studies indicated longterm control activity of tricyclazole by foliar spray and soil drench in the transplant flat. ${ }^{50}$ ) The combination of these treatments was indicated to reduce the frequency of protectant application on a full-season control basis.

Studies on action mechanism of tricyclazole are now in progress. In the course of study on the suppression of pathogenicity by tricyclazole, Sisler and co-workers have found the 


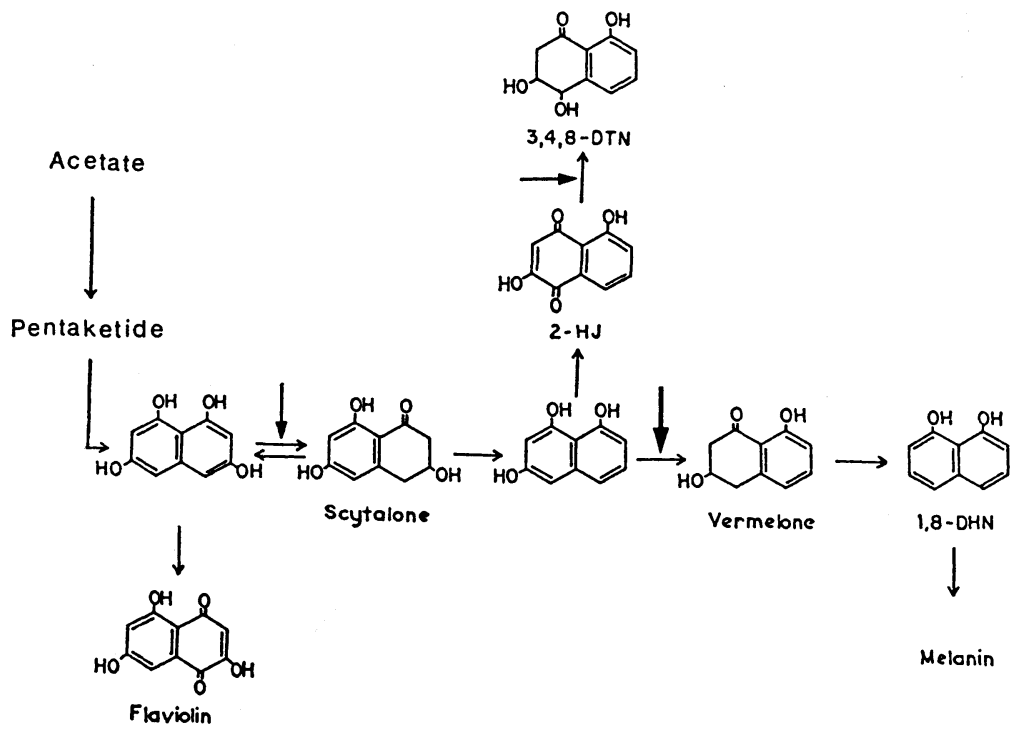

Fig. 3 Site of inhibition by tricyclazole in the proposed melanin biosynthetic pathway with associated branch in $P$. oryzae.

intriguing fact that the chemical specifically inhibits the melanin synthesis in $P$. oryza $e^{63,64)}$ (Fig. 3). While the fungal production of pyricurol, a prominent phytotoxic substance formed via polyketide pathway as melanin, was not inhibited by tricyclazole, the biosynthesis of vermelone, a late intermediate in allomelanin synthesis, was totally inhibited by the chemical at concentrations as low as 0.01 $\mu \mathrm{g} / \mathrm{ml}$. As a result of this inhibition, predominant accumulation of scytalone, 2-hydroxyjuglone $(2-\mathrm{HJ})$ and 3,4-dihydro-3,4,8trihydroxy - 1 (2H) - naphtalenone $(3,4,8$-DTN) was observed. Flaviolin accumulation was also induced at higher concentrations of tricyclazole $(1-10 \mu \mathrm{g} / \mathrm{ml})$, whereas that of $3,4,8-D T N$ was depressed at this concentration level, indicating the presence of a secondary site of inhibition in the pathways ${ }^{64}$ (Fig. 3).

Although a correlation between inhibition of melanization and blast-control effect has not yet been established, the buff mutants of $P$. oryzae were shown to phenotypically resemble the tricyclazole-treated wild-type strain and were essentially nonpathogenic to rice plant. ${ }^{64)}$ The results suggest that a melanin biosynthetic pathway or related secondary metab- olism is involved in the pathogenicity of $P$. oryzae. A different action mechanism of tricyclazole was proposed by Shiba and Nagata, that an antifungal substance was produced in rice leaves treated with the chemical. ${ }^{62}$ ) There might be an integrated effect in the control of blast disease in vivo, but the finding that tricyclazole inhibits appressorial penetration both into cellophane film and rice sheath cells in almost the same manner ${ }^{65)}$ suggests that the primary site of action is on the pathogen and not on the host plant. In addition, it was indicated that melanization in the appressoria of $P$. oryzae was highly sensitive to tricyclazole with concomitant inhibition of fungal penetration into artificial film. Melanization in $P$. oryzae, therefore, may be an indispensable step for the fungal appressorium to mature and to obtain infestiosity.

Interestingly, several anti-blast chemicals which seem to have similar or identical modes of action have recently been developed in Japan and other countries. Among them, CGA-49104 ${ }^{66)} \quad[1,2,5,6$-tetrahydro-4H-pyrrolo$(3,2,1-i, j)$-quinolin-4-one] and PP 38967) [4,5dihydro-4-methyltetrazolo-(1,5-a)-quinazolin-5one] are promising agents for the control of blast disease. The study of the action me- 
chanism of such chemicals may elucidate the physiology of infection by $P$. oryzae and stimulate the finding of new chemicals with better characteristics in future.

\section{REFERENCES}

1) T. Misato: Jpn. Agric. Res. Q. 1, 11 (1967)

2) K. Goto: "Proc. Symp. Int. Rice Res. Inst.," Johns Hopkins Press, Baltimore, p. 195, 1965

3) H. Miura, H. Ito \& S. Takahashi: Ann. Phytopathol. Soc. Jpn. 41, 415 (1975)

4) T. Yaoita, N. Go, K. Aoyagi \& H. Sakurai: ibid. 43, 357 (1977) (Abstr.)

5) M. Katagiri, Y. Uesugi \& Y. Umehara: $J$. Pesticide Sci. 5, 417 (1980)

6) S. Takeuchi, K. Hirayama, K. Ueda, H. Sakai \& H. Yonehara: J. Antibiot., Ser. A 11, 1 (1958)

7) T. Misato, I. Ishii, M. Asakawa, Y. Okimoto \& K. Fukunaga: Ann. Phytopathol. Soc. Jpn. 24, 302 (1959)

8) M. Asakawa, T. Misato \& K. Fukunaga: Noyaku Seisan Gijutsu 8, 24 (1963)

9) H. Yonehara \& N. Ōtake: Tetrahedron Lett. 3785 (1966)

10) H. Seto, I. Yamaguchi, N. Otake \& H. Yonehara: Agric. Biol. Chem. 32, 1292 (1968)

11) T. Misato, I. Ishii, M. Asakawa, Y. Okimoto \& K. Fukunaga: Ann. Phytopathol. Soc. Jpn. 26, 19 (1961)

12) T. Misato, Y. Okimoto, I. Ishii, M. Asakawa \& K. Fukunaga: ibid. 26, 25 (1961)

13) K. T. Huang, T. Misato \& H. Asuyama: J. Antibiot., Ser. A 17, 65 (1964)

14) H. Yamaguchi \& N. Tanaka: J. Biochem. 60, 632 (1966)

15) H. Seto, N. Ōtake \& H. Yonehara: Agric. Biol. Chem. 30, 877 (1966)

16) I. Yamaguchi, H. Shibata, H. Seto \& T. Misato: J. Antibiot. 28, 7 (1975)

17) H. Yonehara, H. Seto, S. Aizawa, T. Hidaka, A. Shimazu \& N. Ōtake: ibid. 21, 369 (1968)

18) T. Sugimoto: Nihon Nōson Igakukai Zasshi 21, 316 (1972)

19) I. Yamaguchi, K. Takagi \& T. Misato: Agric. Biol. Chem. 36, 1719 (1972)

20) K. Takagi, T. Kojima, K. Shibuya, E. Ebata, T. Koizumi \& H. Kishida: Nippon Nôgeikagaku Kaishi 44, 512 (1970)

21) H. Umezawa, Y. Okami, T. Hashimoto, Y. Suhara, M. Hamada \& T. Takeuchi: J. Antibiot., Ser. A 18, 101 (1965)

22) Y. Suhara, F. Sasaki, K. Maeda, H. Umezawa \& M. Ohno: J. Am. Chem. Soc. 90, 6559 (1968)

23) T. Ishiyama, I. Hara, M. Matsuoka, K. Saito,
S. Shimada, R. Izawa, T. Hashimoto, M. Hamada, Y. Okami, T. Takeuchi \& H. Umezawa: J. Antibiot., Ser. A 18, 115 (1965)

24) H. Miura \& S. Takahashi: Ann. Phytopathol. Soc. Jpn. 42, 372 (1976)

25) N. Tanaka, H. Yamaguchi \& H. Umezawa: J. Biochem. 60, 429 (1966)

26) K. T. Huang, Y. Hoshino \& T. Misato: Ann. Phytopathol. Soc. Jpn. 35, 134 (1969) (Abstr.)

27) M. Kado, T. Maeda, E. Yoshinaga, T. Iwakura \& T. Uchida: ibid. 30, 109 (1965) (Abstr.)

28) M. Kado, T. Maeda, E. Yoshinaga, Y. Takahashi \& H. Yamamoto: ibid. 34, 188 (1968) (Abstr.)

29) Y. Yamada \& I. Takase: ibid. 34, 199 (1968) (Abstr.)

30) I. Takase: Noyaku Kenkyu 25, 49 (1978)

31) K. Taninaka, H. Kurono, T. Hara \& K. Murata: J. Pesticide Sci. 1, 115 (1976)

32) M. Katagiri \& Y. Uesugi: Phytopathology 67, 1415 (1977)

33) T. Maeda, H. Abe, K. Kakiki \& T. Misato: Agric. Biol. Chem. 34, 700 (1970)

34) M. A. de Waard: Maded. Landbouwhogesch. Wageningen 74-14, 45 (1974)

35) O. Kodama, H. Yamada \& T. Akatsuka: Agric. Biol. Chem. 43, 1719 (1979)

36) O. Kodama, K. Yamashita \& T. Akatsuka: ibid. 44, 1015 (1980)

37) H. Nakamura: Rev. Plant Protec. Res. 10, 1 (1977)

38) F. Araki and Y. Miyagi: Ann. Phytopathol. Soc. Jpn. 42, 401 (1976)

39) K. Kakiki \& T. Misato: J. Pesticide Sci. 4, 305 (1979)

40) K. Kakiki \& T. Misato: ibid. 4, 129 (1979)

41) Y. Uesugi: Jpn. Agric. Res. Q. 7, 185 (1973)

42) C. Tomizawa \& Y. Uesugi: Agric. Biol. Chem. 36, 294 (1972)

43) Y. Uesugi \& C. Tomizawa: ibid. 35, 941 (1971)

44) Y. Uesugi, M. Katagiri \& O. Noda: ibid. 38, 907 (1974)

45) Y. Uesugi, O. Kodama \& T. Akatsuka: ibid. 42, 2181 (1978)

46) H. Yamamoto, C. Tomizawa, Y. Uesugi \& T. Murai: ibid. 37, 1553 (1973)

47) I. Ueyama, Y. Uesugi, C. Tomizawa \& T. Murai: ibid. 37, 1543 (1973)

48) T. Watanabe, H. Igarashi, K. Matsumoto, K. Seki, S. Mase \& Y. Sekizawa: J. Pesticide Sci. 2, 291 (1977)

49) M. Ishida \& K. Nambu: Noyaku Kagaku 3, 10 (1975)

50) J. D. Froyd, C. J. Paget, L. R. Guse, B. A. Dreikorn \& J. L. Pafford: Phytopathology 66, 1135 (1976) 
51) M. Uchiyama, H. Abe, R. Sato, M. Shimura \& T. Watanabe: Agric. Biol. Chem. 37, 737 (1973)

52) T. Watanabe: J. Pesticide Sci. 2, 395 (1977)

53) T. Watanabe, Y. Sekizawa, M. Shimura, Y. Suzuki, K. Matsumoto, M. Iwata \& S. Mase: ibid. 4, 53 (1979)

54) M. Iwata, Y. Suzuki, T. Watanabe, S. Mase \& Y. Sekizawa: Ann. Phytopathol. Soc. Jpn. 46, 297 (1980)

55) Y. Sekizawa \& S. Mase: J. Pesticide Sci. 6, 91 (1981)

56) H. Sumi, Y. Takahi, Y. Kondo \& K. Nakagami: Ann. Phytopathol. Soc. Jpn. 34, 114 (1968)

57) M. Ishida: "Environmental Toxicology of Pesticides," ed. by F. Matsumura, G. M. Boush \& T. Misato, Academic Press, London, p. 281, 1972

58) T. Tokuda, M. Nishiki, H. Hoshi, K. Shinoda, M. Ishida \& T. Misato: J. Pesticide Sci. 1, 283
(1976)

59) K. Aoki: ibid. 6, 355 (1981) (in Japanese)

60) H. Oku \& H. Sumi: Ann. Phytopathol. Soc. Jpn. 34, 250 (1968)

61) T. Chida, T. Uekita, K. Satake, K. Hirano, K. Aoki \& T. Noguchi: ibid. 48, 58 (1982) (Abstr.)

62) Y. Shiba \& T. Nagata: ibid. 47, 662 (1981)

63) M. C. Tokousbalides \& H. D. Sisler: Pestic. Biochem. Physiol. 8, 26 (1978)

64) C. P. Woloshuk, H. D. Sisler, M. R. Tokousbalides \& S. R. Dutky: ibid. 14, 256 (1980)

65) I. Yamaguchi, S. Sekido \& T. Misato: $J$. Pesticide Sci. (in contribution)

66) F. Schwinn, M. Nakamura \& G. Handschin: 9th Int. Congr. Plant Protect. 1979, Abstracts, 479, 1979

67) M. C. Shephard \& S. R. Ramaswamy: 3rd Int. Congr. Plant Pathol. 1978, Abstracts, 358, 1978 